\title{
Fungus-Mediated Synthesis of magnetic nanoparticles for immobilisation of Pectolytic and xylanolytic enzymes
}

\author{
Shady S. Hassan ${ }^{1,2^{*}}$, Gwilym A. Williams ${ }^{2}$, and Amit K. Jaiswal ${ }^{2}$ \\ ${ }^{1}$ School of Food Science and Environmental Health, College of Sciences and Health, Technological University Dublin, \\ Cathal Brugha Street, Dublin 1, Republic of Ireland. \\ ${ }^{2}$ School of Biological Sciences and Health Sciences, College of Sciences and Health, Technological University Dublin, \\ Kevin Street, Dublin 8, Republic of Ireland. \\ * Correspondence: Shady.Hassan@tudublin.ie
}

\section{Extended Abstract}

In this study, superparamagnetic iron oxide nanoparticles (SPION) were synthesized using the filtrate of Aspergillus flavus exposed to $\mathrm{Fe}$ (III) and Fe(II) salts in aqueous solution. The extracellular synthesis of SPION was monitored by UVVis spectrophotometer and showed an absorption peak at $310 \mathrm{~nm}$. The morphology of SPION was found to be flakes-like as confirmed by Field Emission Scanning Electron Microscopy (FESEM), while the average crystallite size was $\sim 16 \mathrm{~nm}$ as determined through X-ray diffraction (XRD). Energy dispersive X-ray (EDX) analysis was performed to confirm the presence of elemental $\mathrm{Fe}$ in the sample. Pectinase and xylanase were covalently immobilized on SPION with efficiencies of approximately $84 \%$ and $77 \%$, respectively. Compared to the free enzymes, the immobilized enzymes were found to exhibit enhanced tolerance to the variation of $\mathrm{pH}$ and temperature, and improved storage stability. Furthermore, the residual activity of immobilized enzymes was approximately $56 \%$ for pectinase and $52 \%$ for xylanase, after four and three consecutive cycles, respectively. 